\title{
The Boundaries of Development
}

\author{
Thomas Pradeu • Lucie Laplane • Michel Morange • \\ Antonine Nicoglou $\cdot$ Michel Vervoort
}

Published online: 9 November 2011

(c) Konrad Lorenz Institute 2011

This thematic section of Biological Theory is focused on development; it raises the problem of the temporal and spatial boundaries of development. From a temporal point of view, when does development start and stop? From a spatial point of view, what is it exactly that "develops," and is it possible to delineate clearly the developing entity? This section explores the possible answers to these questions, and thus sheds light on the definition of development itself.

According to the traditional view, development refers to the process through which a fertilized egg gives rise to an adult organism. This traditional definition offers an immediate answer to the problem examined here, that of the temporal and spatial boundaries of development. Temporally, development starts with fertilization and ends at adulthood-usually defined as the stage at which the reproductive capacity has been acquired. Spatially, what

T. Pradeu $(\bowtie)$

Paris-Sorbonne University, IHPST, and Institut Universitaire de France, Paris, France

e-mail: thomas.pradeu@paris-sorbonne.fr

L. Laplane

Department of Human Sciences, Gustave Roussy Hospital,

University Paris Ouest Nanterre La Défense, Paris, France

M. Morange

Centre Cavaillès, Ecole normale supérieure,

Paris Cedex 05, France

\section{A. Nicoglou}

Pantheon-Sorbonne University, IHPST, Paris, France

M. Vervoort

Institut Jacques Monod, Paris Diderot University, and Institut Universitaire de France, Paris, France develops is an organism, seen as the product of internal, preexisting capacities found in the egg.

However, this traditional definition and, as a consequence, this traditional conception of the boundaries of development have recently been put into question. As far as the temporal aspects are concerned, it has recently been suggested that development, far from being accomplished at adulthood, lasts all life. Major proponents of this thesis are Gilbert (2002, 2010, 2011), Minelli (2003, 2011), "developmental systems" theorists (Oyama 2000 [1985]; Oyama et al. 2001; Griffiths 2009), and biologists investigating the notion of phenotypic plasticity, first and foremost West-Eberhard (2003).

Concerning the spatial aspects, several biologists and philosophers insist on the necessity of taking into account the crucial influence of the environment on development. They consider that contemporary developmental biology has been excessively "internalist" or even "preformationist," i.e., too much focused on the idea that the organism would be the product of the unfolding of internal potentialities (Oyama 2000 [1985]; Oyama et al. 2001; Lewontin 2000; see also Minelli 2011). Recently, the emerging field of ecological developmental biology ("EcoDevo") has presented new data and new arguments in favor of integrating the role of the environment in development (Gilbert and Epel 2009; see also Gilbert 2002; McFall-Ngai 2002). Together, these biologists and philosophers consider that the spatial boundaries of the developing entity are blurred and need to be redefined, and more generally that we are to modify our conception of what a biological individual is (e.g., Gilbert 2002). Some even hold that the developing entity is, in fact, a system made of the organism plus its environment [e.g., some proponents of developmental systems theory or DST, in particular Griffiths and Gray (2001)]. Yet does insisting on the influence of the 
environment on development amount to claiming that the environment is part of the entity that develops? In this section, we explore the way in which the environment impinges on development, and the consequences of this idea for the delineation of the developing entity.

Of the nine articles that constitute this special section, seven deal with the temporal boundaries of development (Gilbert, Laplane, Minelli, Morange, Nicoglou, Thery, and Vervoort), and two with its spatial boundaries (Maienschein and Pradeu; but note that Minelli also examines some spatial aspects of development). Our intention has been to use specific conceptual tools to try to shed light on the definition of the boundaries of development: mechanisms of genetic regulation, in particular Hox and MicroRNAs (Théry); regeneration (Minelli, Vervoort); metamorphosis (Minelli); stem cells (Laplane); phenotypic plasticity (Nicoglou); aging (Morange); and symbiosis (Pradeu).

Our conviction has been that the debate over the boundaries of development is to a large extent due to a lack of precise definition of the notions involved, in particular, naturally, the notion of "development" itself. To take a telling example, when philosophers and biologists say that development continues throughout a life, what do they call "development"? Most often, they seem to understand development as the construction of an everchanging organism, but then it is almost by definition that development can be said to last until the death of the organism. The common view they reject does not say that the organism stops changing at maturity, but rather that there is something specific to the early stages of the construction of an organism. Part of the problem, therefore, comes from the fact that the two opposing sides are not really answering each other. What the proponents of the critical thesis need, therefore, are good arguments to reject the common view that there is something specific to these early stages of an organism's construction. Thus, several of the articles in this section (in particular Laplane, Morange, Nicoglou, Théry, Vervoort) try to articulate a precise definition of development thanks to a periodization of the construction of an organism, made possible by a focus on specific mechanisms or processes (e.g., genetic regulation, regeneration, metamorphosis, involvement of stem cells, phenotypic plasticity, aging, etc.) Several of them conclude that it is, on the whole, not satisfying to claim that development lasts all life (Laplane, Morange, Nicoglou, Théry, Vervoort), while three articles defend the opposite view (Gilbert, Maienschein, Minelli); but all these answers are anchored in a precise analysis of specific developmental processes. Another possible strategy is to argue that "development" is too equivocal a concept, and therefore needs to be replaced by a series of well-defined terms, such as cleavage, gastrulation, and organogenesis (Pradeu), or else that the referent of the word "development" needs to be specified (Laplane).

Let us now quickly present the articles. Alessandro Minelli claims that no comprehensive theory of development is available yet. He shows the tension between the traditional view of development and processes like metamorphosis or metagenesis, which possess some characteristic features of development. He suggests that a comprehensive theory of development should start with a zero principle of "developmental inertia," corresponding to an indeterminate local self-perpetuation of cell-level dynamics, and illustrates this principle through the analysis of numerous examples.

Frédérique Théry, considering the possibility of defining animal development through genetic regulatory mechanisms, argues that development is characterized by sequential and irreversible changes in gene expression, taking place throughout the organism. This definition implies that at least in some animal species development is not a lifelong process.

Michel Vervoort reports the existence of regenerationspecific processes, and the fact that seemingly similar processes acting during development and regeneration may have differential molecular and cellular bases. He therefore concludes that there are significant differences between regeneration processes in adult animals and developmental processes occurring during earlier phases of the life cycle, precluding the use of the existence of regenerative capabilities in adult animals as an argument in favor of development spanning the whole life.

Antonine Nicoglou gives an account of the different uses of the concept of plasticity and shows that the distinctions between the uses have consequences for the temporal boundaries assigned to development. She proposes a definition of plasticity, as a feature of morphological processes, and offers a way forward for exploring the temporal boundaries of development.

Lucie Laplane develops a species-dependent account of the temporality of development using stem cells as a tool. She distinguishes four different types of temporal boundaries of development depending on species developmental abilities.

Michel Morange describes the recent accumulation of results concerning the "mechanisms of aging." Although aging is related to development, mechanisms of aging are obviously not related to the mechanisms of development. To the contrary, they have characteristics that distinguish them from those of development.

Scott Gilbert explores a phenomenon that has recently led to a temporal expansion of developmental biology into adulthood, namely the production of adult-onset phenotypes by exposure of the fetus or neonate to environmental agents, including maternal nutrients, developmental 
modulators (endocrine disruptors), and maternal care. He suggests that this brings a new, under-appreciated, layer of gene regulation into developmental biology, and demonstrates the poverty of the nature versus nurture framework for discussing phenotype production.

Jane Maienschein asks about the boundary definition of the developing organism: What is an individual organism, and what defines it as the same organism as it changes over time? Through an examination of key concepts such as "organization" and of key actors such as Roux, Driesch, and E.B. Wilson, she offers a detailed account of how this question of the boundaries of the developing organism has been answered historically.

Thomas Pradeu shows that, contrary to the internalist view, the development of an organism in almost all cases implies the presence of "foreign" entities, in particular symbiotic bacteria. He claims that the developing entity is therefore a heterogeneous organism, the spatial boundaries of which can be delineated quite clearly through its immune system.

This series of articles will hopefully confirm that philosophy of developmental biology is an active, deeply conceptual, field-and not only within the much discussed domain of EvoDevo. Determining what development is and what its boundaries are can shed light on key concepts such as individuality, organization, metabolism, and homeostasis.

Acknowledgments These articles resulted from a 2-year working group based at the Institut d'Histoire et de Philosophie des Sciences et des Techniques (IHPST) in Paris. This group gathered Lucie Laplane, Michel Morange, Antonine Nicoglou, Thomas Pradeu, Frédérique Théry, and Michel Vervoort as well as, for some time, Valérie NgoMüller, whose help and kindness have been extraordinary stimulants. We also want to warmly thank Scott Gilbert, Jane Maienschein, and Alessandro Minelli for agreeing to contribute to this section and for their interactions with us throughout the last 2 years. Charles Durand,
Jean Gayon, Thierry Hoquet, Thierry Jaffredo, Francesca Merlin, and Valérie Ngo-Müller made very useful comments on our articles. We also benefited from exchanges with Anthony de Tomaso. We thank the IHPST for hosting our seminar and conferences, and Werner Callebaut for his encouragement and support.

\section{References}

Gilbert SF (2002) The genome in its ecological context. Ann N Y Acad Sci 981:202-218

Gilbert SF (2010) Developmental biology, 9th edn. Sinauer Associates, Sunderland, MA

Gilbert SF (2011) Expanding the temporal dimensions of developmental biology: the role of environmental agents in establishing adult-onset phenotypes. Biol Theory. doi:10.1007/s13752-0110008-0

Gilbert SF, Epel D (2009) Ecological developmental biology: integrating epigenetics, medicine and evolution. Sinauer Associates, Sunderland, MA

Griffiths PE (2009) In what sense does "nothing in biology make sense except in the light of evolution"? Acta Biotheor 57:11-32

Griffiths P, Gray R (2001) Darwinism and developmental systems. In: Oyama S, Griffiths P, Gray R (eds) Cycles of contingency. MIT Press, Cambridge, MA, pp 195-218

Lewontin RC (2000) The triple helix: gene, organism and environment. Harvard University Press, Cambridge, MA

McFall-Ngai M (2002) Unseen forces: the influence of bacteria on animal development. Dev Biol 242:1-14

Minelli A (2003) The development of animal form. Cambridge University Press, Cambridge

Minelli A (2011) Animal development: an open-ended segment of life. Biol Theory. doi:10.1007/s13752-011-0002-6

Oyama S ([1985] 2000) The ontogeny of information. Duke University Press, Durham, NC

Oyama S, Griffiths P, Gray R (eds) (2001) Cycles of contingency: developmental systems and evolution. MIT Press, Cambridge, MA

West-Eberhard M-J (2003) Developmental plasticity and evolution. Oxford University Press, Oxford 